\title{
Scopolamine administration and NBM lesions differentially affect performance in an operant discrimination task
}

\author{
JOHN E. DENCOFF and GORDON K. HODGE \\ University of New Mexico, Albuquerque, New Mexico
}

\begin{abstract}
Effects of cholinergic modulation on differential conditioning performance in rats were evaluated in four experiments. Animals were first trained on an operant discrimination task. In Experiment 1, performance was evaluated following different doses of physostigmine (PHY) or scopolamine (SCO). SCO impaired performance in a dose-dependent manner; doses causing moderate impairment were selected for the remainder of the study. In Experiment 2, to test effects of PHY on SCO-impaired animals, rats were tested with injections of SCO $(0.125 \mathrm{mg} / \mathrm{kg})$ plus saline, injections of SCO $(0.125 \mathrm{mg} /$ $\mathrm{kg}$ ) plus PHY $(0.03125 \mathrm{mg} / \mathrm{kg})$, or two injections of saline. SCO reduced total responding, but PHY failed to attenuate the effect. Although SCO decreased performance, response patterns suggested that discrimination ability per se was unaffected. In Experiment 3, animals were given bilateral lesions of the nucleus basalis magnocellularis (NBM); performance was reassessed with or without PHY $(0.03125 \mathrm{mg} / \mathrm{kg})$ or SCO $(0.125 \mathrm{mg} / \mathrm{kg})$. Lesions alone did not affect total responding; but discrimination ability was impaired, as reflected by reduced successes and increased errors. As in Experiment 2, SCO reduced responding without affecting discrimination ability, but PHY did not improve SCO-impaired task performance. In Experiment 4, 12 months after lesions, nondrug performance of animals was reassessed. Control animals showed recovery after one session, whereas lesioned animals took four sessions to show recovery.
\end{abstract}

Cholinergic suppression, induced pharmacologically or by destruction of the nucleus basalis magnocellularis (NBM), interferes with performance of certain tasks (see Dekker, Connor, \& Thal, 1991). In rats, the cholinergic antagonist scopolamine (SCO) interferes with attentional processes (Cheal, 1981), discrimination learning (Kirk, White, \& McNaughton, 1988), encoding and retrieval of spatial working memory (Beatty \& Bierley, 1986; Flicker, Dean, Watkins, Fisher, \& Bartus, 1983), and other memory processes. Lesions of the NBM, an important source of cholinergic input to the neocortex, interfere with performance in T-maze alternation learning (e.g., Hepler, Olton, Wenk, \& Coyle, 1985; Salamone, Beart, Alpert, \& Iverson, 1984; Wozniak, Stewart, Finger, \& Olney, 1989) and passive and active avoidance tasks (e.g., Flicker et al., 1983; Haroutunian, Barnes, \& Davis, 1985; Miyamoto, Shintani, Nagaoka, \& Nagawa, 1985).

In contrast, the cholinergic agonist physostigmine (PHY) has been shown to improve learning of some tasks in humans (see Kopelman, 1986) and to facilitate memory in passive avoidance tasks in both normal (Haroutunian et al., 1985; Santucci, Kanof, \& Haroutunian, 1989)

This study was supported by a Sigma Xi Scientific Research Society Grant-in-Aid of Research to J.E.D. and by UNM RAC Grant 1-02396 to G.K.H. A. E. Butt, M. J. Lee, and B. G. Cooper provided technical and surgical assistance. Correspondence should be addressed to G. K. Hodge, Department of Psychology, Logan Hall, University of New Mexico, Albuquerque, NM 87131-1161 (e-mail: ghodge@unm. edu). and NBM-lesioned animals (Haroutunian, Kanof, \& Davis, 1985; Santucci et al., 1989). Murray and Fibiger (1985, 1986) have reported improvement using PHY in NBMlesioned rats on acquisition of T-maze alternation tasks and eight-arm radial maze learning tasks.

Task complexity appears to be a factor in determining apparent effects of cholinergic modulation on memory. For example, although cholinergic suppression impairs performance on passive avoidance and T-maze alternation tasks, it has been argued that such tasks provide somewhat limited measures of memory (e.g., see Bartus, Flicker, Dean, Pontecorvo, \& Figueiredo, 1986). More complex tasks, such as the eight-arm radial maze (Bartus et al., 1986; Murray \& Fibiger, 1985) and delayed matching-tosample tasks (Dunnett, 1985), may offer a wider range of performance scores and a more complete assessment of memory impairments.

We used a relatively complex food-reinforced visualcue operant discrimination task to evaluate the effects of PHY and SCO administration and NBM lesions on task performance. After animals were trained to criterion, performance was first evaluated following different doses of PHY or SCO. Second, selected doses of PHY and SCO were tested in combination. Third, PHY and SCO were evaluated on animals given bilateral radio-frequency (RF) lesions of the NBM (cf. Hepler et al., 1985; Wenk, Cribbs, $\&$ McCall, 1984). Finally, enduring behavioral effects of lesions were assessed 1 year after surgery.

On the basis of previous reports, SCO and NBM lesions were expected to impair discrimination performance, 
as reflected by decreased successes and increased erro rs. By reversing deficits induced by SCO or NBM lesions, PHY was expected to improve performance, whereas lesioned animals given SCO were expected to show exacerbated deficits. Finally, lesion-induced deficits were expected to persist over time.

\section{EXPERIMENT 1}

The purpose of Experiment 1 was to establish baseline learning performance in the differential discrimination task and optimal drug doses for the remainder of the experiments.

\section{Method}

\section{Animals}

Twenty-nine male Harlan Sprague-Dawley rats (Indianapolis, IN) were purchased at 21 days of age and housed individually. They were maintained on a 12:12-h light:dark cycle (lights on at 7:00 p.m.), with food and water available ad libitum except during periods of training or testing.

\begin{abstract}
Apparatus
Training and testing were conducted in Gerbrandt model D operant chambers (Arlington, MA) measuring $20 \times 22 \times 24 \mathrm{~cm}$. In each chamber, two cue lights ( $5-\mathrm{W}$ clear bulbs) were horizontally positioned approximately $10 \mathrm{~cm}$ apart, $4 \mathrm{~cm}$ above the barpress lever; the target light (TL) was to the right, the dist ractor light (DL) to the left. A 5-W red lightbulb provided illumination. Each chamber was housed in a sound-attenuating box, ventilated by an external fan. Reinforcement consisted of one food pellet $(45 \mathrm{mg}$; P. J. Noyes, Lancaster, NH) per correct barpress. Computers controlled the duration and sequence of cue lights and recorded all data from testing and training sessions.
\end{abstract}

\section{Operant Training}

The rats began training after 9 days of acclimation to home cages. The animals were trained on alternate days beginning at approximately 9:00 a.m., one session per day. They were food deprived $22 \mathrm{~h}$ prior to testing but otherwise had free access to food and water. Testing order was counterbalanced to cont rol for duration of food deprivation.

During discrimination learning, barpresses made during presentations of the TL were rewarded (successes), those made during the DL were not (errors). For the first 20 sessions, TL duration was $10 \mathrm{sec}$. The DL was introduced following the 5 th session and remained set at $10 \mathrm{sec}$. Differential discrimination was introduced following the 15 th session. For all subsequent sessions, presses made during DL presentations delayed the onset of the TL an additional $10 \mathrm{sec}$. Beginning with the $21 \mathrm{st}$ session, TL duration was reduced to $7.5 \mathrm{sec}$ for the next 5 sessions, then to $5 \mathrm{sec}$ for 5 sessions, and to $3 \mathrm{sec}$ for all subsequent sessions.

In the final version of the task, the two lights alternated in a continuous pattern (3-sec TL, 10-sec DL). Presses made during DL presentations reset the alternation timer, holding the DL "on" for an additional $10 \mathrm{sec}$ following the incorrect press (time delays were not cumulative, although additional presses reset the alternation timer). There were no intertrial intervals due to the constraints of the computer control system.

Each session lasted for 15 min or until 50 successful responses were made, whichever occurred first. With completion of the 40th session, all animals reached an asymptotic level of performance (50 successes within the $15-\mathrm{min}$ session). Successes and errors were summed to provide a measure of total responding, and total session time was recorded. Successes were divided by total responses to measure percent accuracy.

In order to evaluate learning progress, separate paired-means $t$ tests were conducted on accuracy (successes/total responses), successes, errors, total responding, and session time for each of the operant transitions (i.e., when differential discrimination was added to the operant task, and the three times-7.5, 5 , and $3 \mathrm{sec}-$ when TL duration was successively reduced over trials). Transition sessions were compared with the sessions that immediately preceded them.

\section{Drug Testing}

To test for optimal doses of PHY and SCO for Experiments 2-3, the rats were given several drug trials with interspersed nondrug days. The rats were randomly assigned to one of four PHY groups (saline, $n=7 ; 0.03125-\mathrm{mg} / \mathrm{kg}$ PHY, $n=8 ; 0.0625-\mathrm{mg} / \mathrm{kg}$ PHY, $n=7$; or $0.125-\mathrm{mg} / \mathrm{kg} \mathrm{PHY}, n=7$ ) and tested for operant performance. One day of nondrug testing followed. On the 3 rd test day, the rats were randomly reassigned to one of four high-range $\mathrm{SCO}$ conditions (saline, $n=8 ; 0.250-\mathrm{mg} / \mathrm{kg} \mathrm{SCO}, n=7 ; 0.500-\mathrm{mg} / \mathrm{kg}$ $\mathrm{SCO}, n=7$; or $1.000-\mathrm{mg} / \mathrm{kg} \mathrm{SCO}, n=7$ ) and tested. Another nondrug test day followed, then animals were randomly reassigned to one of four low-range SCO doses (saline, $n=8 ; 0.03125-\mathrm{mg} / \mathrm{kg}$ $\mathrm{SCO}, n=7 ; 0.0625 \mathrm{mg} / \mathrm{kg} \mathrm{SCO}, n=7$; or $0.125-\mathrm{mg} / \mathrm{kg} \mathrm{SCO}, n=$ 7). Data were analyzed by conducting individual analyses of variance (ANOVAs) for each drug day for each measurement (accuracy, successes, errors, total responses, and session time). Separate ANOVAs for each measure were conducted for the intervening nondrug days to control for any possible drug carryover effects. During testing, occasional qualitative observations of performance, activity, and arousal were also noted; observations were made primarily for the purpose of assessing animal viability and gross response to drug treatment.

$\mathrm{SCO} \cdot \mathrm{HCl}$ and $\mathrm{PHY}$ salicylate (Sigma, St. Louis, MO) were freshly prepared in saline vehicle before use. Low PHY and SCO doses were made from stock solutions of the highest doses (i.e., $0.125 \mathrm{mg} / \mathrm{kg}$ for PHY; 1.0 or $0.125 \mathrm{mg} / \mathrm{kg}$ for high- and low-range doses of SCO, respectively; all doses were based on salt weights of drugs). Injections were given intraperitoneally (i.p.) $20 \mathrm{~min}$ before testing.

\section{Results and Discussion}

\section{Operant Training}

For the first transition (addition of a differential discrimination: from $10-\mathrm{sec} \mathrm{TL} / 10-\mathrm{sec} \mathrm{DL}$ to $10-\mathrm{sec} \mathrm{TL} /$ $10-\mathrm{sec}$ DL with a $10-\mathrm{sec}$ delay for DL responses), animals showed decreased accuracy $[t(28)=13.5985, p<$ $.0001]$, decreased successes $[t(28)=5.456, p<.0001]$, increased errors $[t(28)=8.830, p<.0001]$, increased responding over the trial $[t(28)=8.620, p<.0001]$, and increased session time relative to that for the day immediately before transition $[t(28)=9.593, p<.0001]$.

For both the second transition (from 10-sec TL/10-sec DL with delay to 7.5 -sec TL/10-sec DL with delay) and the third transition (from 7.5-sec TL/10-sec DL with delay to $5.0-\mathrm{sec} \mathrm{TL} / 10$-sec DL with delay), no significant differences were observed in accuracy, successes, errors, responding, or session time (see Figure 1).

For the fourth transition (from 5.0-sec TL/10-sec DL with delay to $3.0-\mathrm{sec}$ TL/10-sec DL with delay), rats showed decreased accuracy $[t(28)=4.8135, p<.0001]$, increased errors $[t(28)=3.846, p<.0006]$, increased re- 



Figure 1. Behavioral performance during initial drug testing. PHY, physostigmine; HI-SCO, high-dose series of scopolamine; LO-SCO, low-dose series of scopolamine. All comparisons are versus the saline condition within each test condition. ${ }^{*} p<.05 . \quad{ }^{* *} p<.01 . \quad{ }^{* * *} p<$ .001 . sponding $[t(28)=3.846, p<.0006]$, and increased session time $[t(28)=7.861, p<.0001]$; no differences were observed for successes.

\section{Drug Testing}

Physostigmine trial. No significant effects were observed across the PHY trial; however, as PHY increased, successes gradually decreased, errors increased, responding decreased, and session time increased (Figure 1).

Scopolamine high-dose trial. Qualitatively, animals given SCO did not seem as active in the test chamber on nondrug days or when compared with rats given saline. They were, however, still able to barpress, and they readily consumed food upon return to their cages.

Overall, in high-dose trials (Figure 1), SCO decreased accuracy $[F(3,25)=3.45, p<.0317]$, reduced successes $[F(3,25)=62.06, p<.0001]$, reduced errors $[F(3,25)=$ $2.88, p<.05]$, reduced responding $[F(3,25)=28.18, p<$ $.0001]$, and increased session time $[F(3,25)=26.93, p<$ $.0001]$. Post hoc comparisons showed that, compared with rats given saline, rats given any of the high doses of SCO made fewer successes $[F(1,28)=154.23, p<$ .0001 , for $1.0 \mathrm{mg} / \mathrm{kg} ; F(1,28)=108.02, p<.0001$, for $0.5 \mathrm{mg} / \mathrm{kg}$; and $F(1,28)=83.21, p<.0001$, for $0.25 \mathrm{mg} /$ $\mathrm{kg}$, fewer errors $[F(1,28)=5.70, p<.02$, for $1.0 \mathrm{mg} / \mathrm{kg}$; $F(1,28)=4.55, p<.04$, for $0.5 \mathrm{mg} / \mathrm{kg}$; and $F(1,28)=$ $6.27, p<.02$, for $0.25 \mathrm{mg} / \mathrm{kg}]$, and fewer responses $[F(1,28)=67.11, p<.0001$, for $1.0 \mathrm{mg} / \mathrm{kg} ; F(1,28)=$ $48.57, p<.0001$, for $0.5 \mathrm{mg} / \mathrm{kg}$; and $F(1,28)=44.28, p<$ .0001 , for $0.25 \mathrm{mg} / \mathrm{kg}$, and they took more time at the task $[F(1,28)=52.06, p<.0001$, for $1.0 \mathrm{mg} / \mathrm{kg} ; F(1,28)=$ $52.06, p<.0001$, for $0.5 \mathrm{mg} / \mathrm{kg}$; and $F(1,28)=52.06, p<$ .0001 , for $0.25 \mathrm{mg} / \mathrm{kg}$ ].

Scopolamine low-dose trial. Overall (see Figure 1), SCO reduced accuracy $[F(3,25)=5.53, p<.0047]$, reduced successes $[F(3,25)=8.55, p<.0004]$, reduced errors $[F(3,25)=3.87, p<.02]$, reduced responding $[F(3,25)=7.31, p<.001]$, and increased session time $[F(3,25)=6.57, p<.002]$. Post hoc comparisons showed that of the three lower doses of SCO, only $0.125-\mathrm{mg} / \mathrm{kg}$ SCO resulted in fewer successes than did saline $[F(1,28)=$ $23.33, p<.0001]$. All three low-dose SCO groups made fewer errors than did saline animals $[F(1,28)=5.10, p<$ .03 , for $0.125-\mathrm{mg} / \mathrm{kg} \mathrm{SCO} ; F(1,28)=6.98, p<.01$, for $0.0625-\mathrm{mg} / \mathrm{kg} \mathrm{SCO}$; and $F(1,28)=9.46, p<.005$, for $0.0325-\mathrm{mg} / \mathrm{kg} \mathrm{SCO}$. Each low-dose SCO group made fewer responses than did saline animals $[F(1,28)=21.04$, $p<.0001$, for $0.125-\mathrm{mg} / \mathrm{kg} \mathrm{SCO} ; F(1,28)=8.77, p<$ .007 , for $0.0625-\mathrm{mg} / \mathrm{kg} \mathrm{SCO}$; and $F(1,28)=6.46, p<$ .02 , for $0.0325-\mathrm{mg} / \mathrm{kg} \mathrm{SCO}$. Additionally, rats in the $0.0625-\mathrm{mg} / \mathrm{kg}$ and $0.125-\mathrm{mg} / \mathrm{kg} \mathrm{SCO}$ conditions took more time than did those given saline $[F(1,28)=13.99$, $p<.001$; and $F(1,28)=14.57, p<.0008$, respectively]. No significant differences were observed across the interspersed nondrug days.

The delay that penalized rats for incorrect responses was more difficult for rats to learn than were the successive reductions in TL presentation. It is arguable that the added delay presented a more difficult problem for the 
rats than did the successive TL reductions, which were primarily dependent on animals' reaction speeds. However, the rats showed decreased accuracy, increased errors, increased responding, and increased session time with the final transition to the $3.0-\mathrm{sec} \mathrm{TL} / 10-\mathrm{sec} \mathrm{DL}$ with delay, suggesting that the 3.0 -sec TL response window was close to the performance threshold for this task.

In a dose-dependent manner, SCO decreased not only successes but errors as well; the primary effect of SCO was to reduce responding. PHY seemed to impair performance, although not significantly, perhaps because the rats were initially performing at ceiling levels and an increased arousal state might have negatively influenced performance. Our primary concern was to avoid doses that were too high and would thereby impair performance and to select a dose capable of restoring impaired functions brought about by SCO or lesions in later experiments. PHY at $0.03125 \mathrm{mg} / \mathrm{kg}$ was selected for the remaining experiments because it was comparable to doses used by others to significantly improve performance in similar tasks (cf. Santucci et al., 1989).

\section{EXPERIMENT 2}

Insofar as SCO interferes with behavior by inhibiting acetylcholine ( $\mathrm{ACh}$ ) systems, PHY might be expected to reverse these effects. The purpose of Experiment 2 was to determine whether PHY would reverse the effects of SCO.

\section{Method}

One week following Experiment 1 , rats ( $n=29$; weighing 360$390 \mathrm{~g}$ ) were randomly assigned to one of three drug-treatment conditions in a repeated measures design. The nondrug (NON) day immediately preceding the randomized block, as shown in Figure 2, was selected for visual reference but was not included in the statistical design. On different days, animals received double injections of saline (S-S), saline plus SCO (S-SCO, $0.125 \mathrm{mg} / \mathrm{kg}$ ), or $\mathrm{SCO}(0.125 \mathrm{mg} / \mathrm{kg})$ plus PHY (SCO-PHY, $0.03125 \mathrm{mg} / \mathrm{kg}$ ). Nondrug trials were interspersed between each drug-testing day. Data was analyzed using one-factor repeated measures ANOVAs with single-degree-of-freedom post hoc contrasts for the drug-testing block. Nondrug days were analyzed separately using a one-factor repeated measures ANOVA. All drugs were prepared as in Experiment 1 , with doses based on salt weights.

\section{Results and Discussion}

SCO depressed performance, but PHY was ineffective in reversing SCO-impaired behavior. As shown in Figure 2, animals given injections of S-SCO or SCO-PHY showed increased accuracy $[F(2,56)=4.06, p<.0304]$, reduced successes $[F(2,56)=53.37, p<.0001]$, decreased errors $[F(2,56)=17.31, p<.0001]$, reduced responding $[F(2,56)=49.57, p<.0001]$, and increased session times $[F(2,56)=72.50, p<.0001]$. Post hoc contrasts showed that, compared with animals in the S-S condition, animals in the S-SCO condition made significantly fewer successes $[F(1,28)=117.88, p<.0001]$, fewer errors $[F(1,28)=28.08, p<.0001]$, and fewer responses $[F(1,28)=105.89, p<.0001]$, and they took
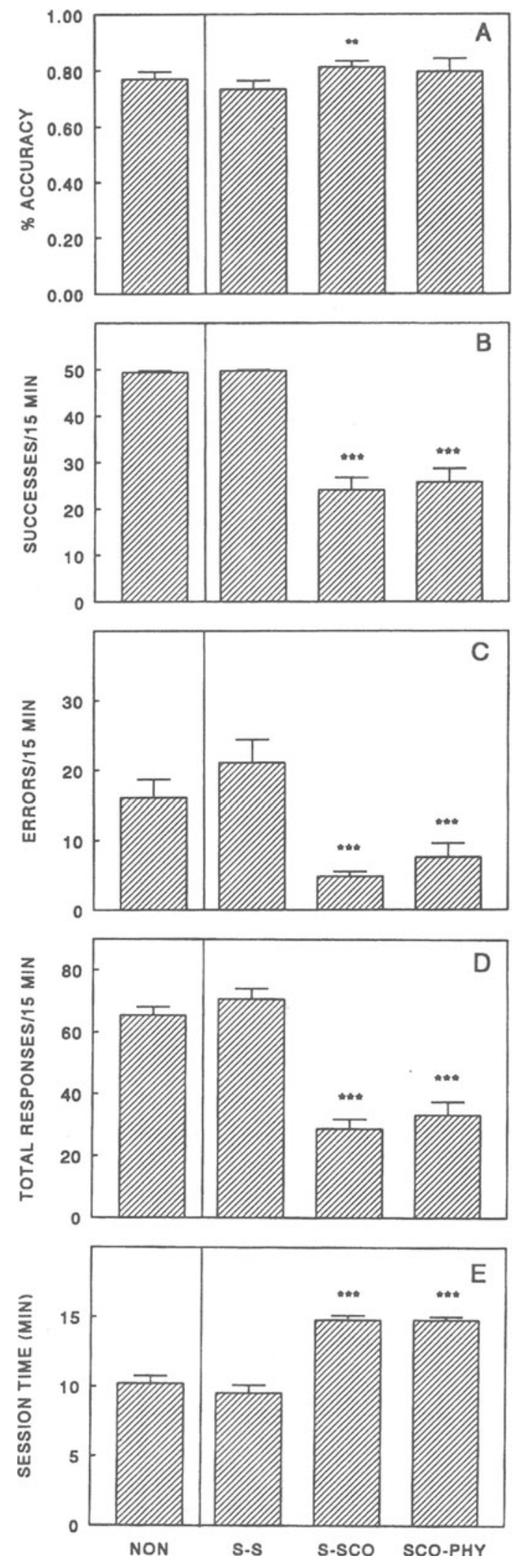

Figure 2. Scopolamine significantly decreased successes, errors, and total responses, but it increased accuracy and session time as compared with nondrug and dual saline injections. NON, nondrug; S-S, saline-saline; S-SCO, saline-scopolamine; SCO-PHY, scopolamine-physostigmine. ${ }^{* *} p<.01 . \quad{ }^{* * *} p<.001$. 
more time $[F(1,28)=77.32, p<.0001]$ and had increased accuracy $[F(1,28)=8.44, p<.008]$. The pattern was the same for post hoc contrasts of S-S with SCOPHY: fewer successes $[F(1,28)=68.45, p<.0001]$, fewer errors $[F(1,28)=14.17, p<.0008]$, fewer responses $[F(1,28)=46.79, p<.0001]$, and longer session times $[F(1,28)=89.98, p<.0001]$, but no change in accuracy. No drug carryover effects were observed between test days. As with Experiment 1, when animals were given SCO (in combination with saline or PHY), they did not actively explore the chamber. They were, however, still able to barpress and they consumed food readily upon return to their cages.

On the basis of the results from Experiment 1, we expected that SCO-treated animals would show decreased accuracy, decreased successes, decreased errors, increased session time, and increased total responses. Unexpectedly, accuracy was significantly increased. However, with the perspective afforded by success, error, response, and session time data, it is clear that SCO impaired performance. Successes, errors, and total responses were greatly decreased, and session time was increased; although the ratio of successes to total responses resulted in a significantly higher accuracy, this was probably an artifact. Although previous reports have attributed the effects of SCO, in part, to impaired attention or discrimination processes (see Bartus et al., 1986; Brown \& Warburton, 1971), and our results would be consistent with an attentional deficit interpretation (decreased successes and overall responding), discrimination performance was not appreciably affected. Had discrimination been disrupted, we should have seen decreases in successes with concomitant increases in errors and overall responding; accordingly, accuracy would have been decreased. In the initial training of these animals, we noted that this was the general pattern when the discrimination phase was introduced. Since the DL is presented for longer periods than the $\mathrm{TL}$, there is more opportunity to press during the DL than during the TL. If discrimination were affected in SCO-impaired animals, initially they would have been expected to barpress more during the $\mathrm{DL}$ and less during the TL, resulting in decreased successes and increased errors. However, we observed that SCO decreased both successes and errors, indicating that its primary effect was to disrupt responding, not discrimination.

PHY did not reverse SCO-induced deficits in our task. Although PHY has been shown to facilitate learning and memory in simpler tasks at doses comparable to or higher than those used here (e.g., Haroutunian, Barnes, \& Davis, 1985; Haroutunian, Kanof, \& Davis, 1985; Murray \& Fibiger, 1985), it has proven ineffective in relatively more complex tasks at comparable doses (Robbins et al., 1989); therefore, the complexity of our task may have precluded the ameliorative effects of PHY. It is also possible that our PHY dose may have been too low with respect to the SCO dose. Although we chose a dose that would not disrupt behavior in our task, this dose of
PHY was small relative to doses that some researchers have tested with other methods of ACh inhibition (cf. Murray \& Fibiger, 1985).

\section{EXPERIMENT 3}

Although PHY was ineffective in reversing SCOinduced impairments in responding, $\mathrm{PHY}$ has been reported effective in attenuating lesion-induced impairments (Murray \& Fibiger, 1985, 1986). Accordingly, at the conclusion of Experiment 2, animals were given lesions of the NBM and tested with and without PHY or SCO. Coordinates for the NBM were taken from Hepler et al. (1985) and Wenk et al. (1984); lesions centered on this site are known to produce extensive ACh depletion in the neocortex (Hepler et al., 1985). We have used ibotenic and quisqualic acids to lesion the NBM (Butt, Dencoff, Cooper, Nopp-Dvorak, \& Hodge, 1990; Butt \& Hodge, 1994, 1995), but the extent of such lesions is not always apparent; for example, ibotenic acid may not be completely specific to ACh-producing neurons and may affect task performance in other ways (Marston, Garcha, Robbins, \& Stolerman, 1992). Although damaging fibers of passage, RF lesions destroy neuronal perikarya completely, significantly reducing neocortical ACh levels (Hepler et al., 1985). The purpose of Experiment 3 was to determine whether, as with ibotenic acids lesions (Murray \& Fibiger, 1985, 1986), PHY would attenuate RF-lesion-induced behavioral impairments and to determine whether SCO would exacerbate RF-lesion-induced impairments.

\section{Method}

Following the final set of drug injections in Experiment 2, operant performance was observed over five trials, with the fifth trial constituting baseline performance (BASE). The rats were randomly assigned to one of two groups: the control group $(n=12)$ consisted of sham surgery and nonsurgery animals; the lesioned group $(n=17)$ received bilateral NBM lesions. Animals were then tested following injections of SCO, PHY, or saline (SAL). SCO was expected to further depress lesion-induced impairments, whereas PHY was expected to improve performance of lesioned animals.

\section{Surgery}

The rats were anesthetized using a 4\% Halothane/oxygen mix at 41 per minute for 5 minutes. The animals were placed in a Kopf stereotaxic instrument with incisor bar at $-2.0 \mathrm{~mm}$. Anesthesia was maintained using a $1.5 \%-2.0 \%$ Halothane mix, delivered at $1.5-2.0 \mathrm{~L}$ per minute. Bilateral craniotomies were performed and an electrode $(0.6 \mathrm{~mm}$ diameter, insulated except for $0.5 \mathrm{~mm}$ at the tip) was lowered to $2.8 \mathrm{~mm}$ lateral to midline, $0.8 \mathrm{~mm}$ posterior to bregma, and $6.9 \mathrm{~mm}$ below dura (Hepler et al., 1985). Lesions were made with a Radionics radio-frequency lesion generator (David Kopf, Tujunga, CA). Current was gradually increased to $16 \mathrm{~mA}$ over a 1 -min period, left at $16 \mathrm{~mA}$ for $1 \mathrm{~min}$, turned off, and the electrode was withdrawn after $1 \mathrm{~min}$. Sham surgery was identical, but no current was applied.

\section{Drug Testing}

Following a 2-week post surgical recovery, both groups were tested on the 3-sec TL/10-sec DL with 10-sec delay schedule. Behavioral measures were recorded as in Experiments 1 and 2. The 
rats then received SAL, PHY $(0.03125 \mathrm{mg} / \mathrm{kg})$, or $\mathrm{SCO}$ $(0.125 \mathrm{mg} / \mathrm{kg})$ according to a random block design. As in Experiments $l$ and 2 , nondrug trials occurred between drug-testing days. Simple $t$ tests were conducted on the BASE day to assess any preexisting differences between animals selected as controls or for surgery. Separate repeated measures ANOVAs with single-degreeof-freedom post hoc contrasts were conducted for the randomized drug-testing block. Separate repeated measures ANOVAs were also conducted over just the interspersed nondrug days to assess for possible drug carryover effects.

\section{Results and Discussion}

\section{Postsurgical Data}

Six animals from the lesioned group lost significant weight following surgery. One was euthanized the day following surgery due to self-injurious stereotypy; histology of this animal revealed lesions that encroached upon the globus pallidus and the caudate putamen. The other 5 animals were fed a soft food mash. Within 5 days, 3 resumed eating; but 2 rats failed to recover and were subsequently euthanized. Histology revealed that the latter 2 had improperly centered, large lesions. All other animals appeared healthy, active, and alert, although every lesioned animal showed an initial weight loss during recovery, which persisted for approximately 2 weeks.

\section{Drug Testing}

Behavioral measures were analyzed using multiple one-between- and one-within-subjects ANOVA tests (one each for successes, errors, total responding, and session time). Nonsurgery and sham surgery animals were not significantly different on any measure; they were combined (controls) for statistical purposes. Five rats were not included in statistical comparisons; 3 rats in the lesioned group, one of which was fed the soft food mash, weighed significantly less than other animals, had large, improperly centered lesions, and no longer performed the operant response following surgeries. Because of equipment failure during drug administration, data for 2 control rats were not used. No presurgery (BASE) differences were found between the animals selected for control $(n=10)$ and the lesioned animals $(n=11)$.

Between-groups effects. As shown in Figure 3, relative to controls, overall tests showed that lesions decreased accuracy $[F(1,19)=4.35, p<.05]$, decreased successes $[F(1,19)=7.76, p<.0118]$, increased errors $[F(1,19)=3.94, p<.0619]$, and increased session times $[F(1,19)=8.08, p<.0104]$. Newman-Keuls post hoc comparisons showed that, relative to controls, lesions reduced accuracy in SAL $(p<.05)$ and PHY $(p<.05)$ conditions, reduced successes for all postsurgery conditions $(p<.05$ for Conditions SAL, PHY, and SCO), increased errors for SAL $(p<.05)$ and PHY $(p<.05)$ conditions, and increased session time for the PHY condition $(p<.05)$.

Within-groups effects. Overall, within-groups effects were observed for successes $[F(2,38)=77.99, p<$ $.0001]$, errors $[F(2,38)=5.78, p<.0064]$, total responding $[F(2,38)=49.76, p<.0001]$, and session time
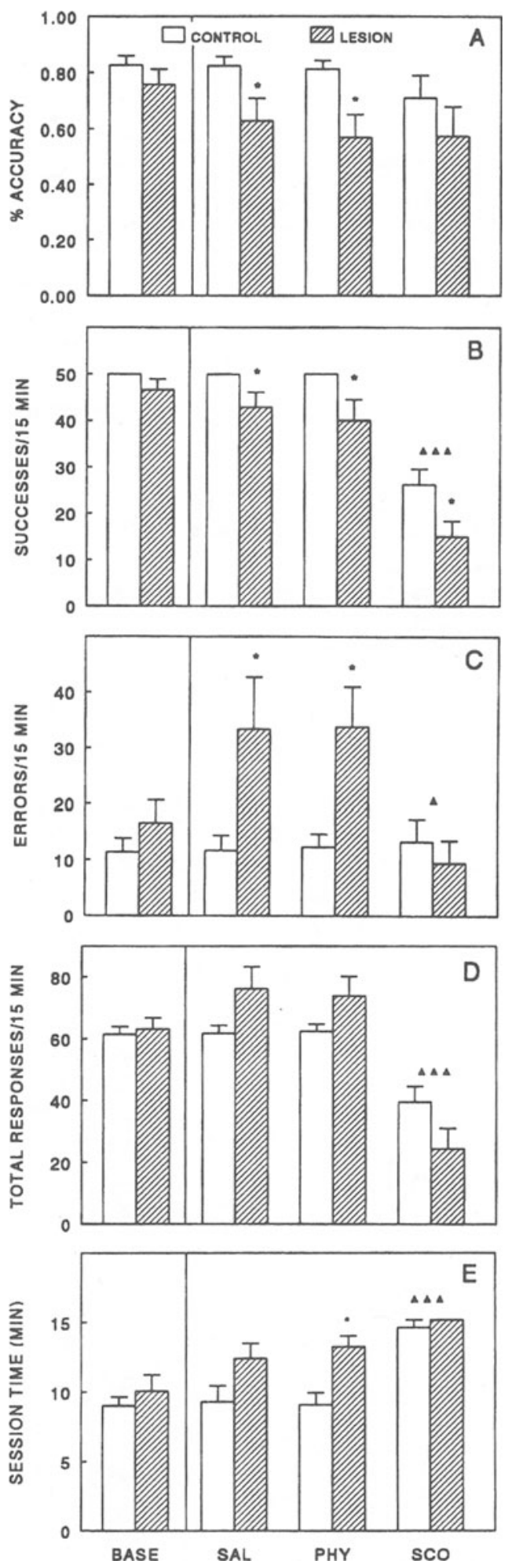

Figure 3. NBM lesions, irrespective of physostigmine treatment, disrupted discrimination performance, whereas scopolamine impaired responding in general, irrespectiye of lesion condition. BASE, prelesion baseline; SAL, postlesion saline treatment; PHY, postlesion physostigmine $(0.03125 \mathrm{mg} / \mathrm{kg})$ treatment; $\mathrm{SCO}$, postlesion scopolamine $(0.125 \mathrm{mg} / \mathrm{kg})$ treatment. Comparison between control (sham and nonsurgery) and lesioned groups: ${ }^{*} p<.05$. Comparison within groups: $\Delta p<.05 ; \Delta \Delta \Delta p<.001$. 
$[F(2,38)=24.78, p<.0001]$. No within-groups effects were observed for accuracy. Single-degree-of-freedom post hoc contrasts showed that SCO significantly reduced successes $(p<.0001)$, reduced errors $(p<.0226)$, reduced total responding $(p<.0001)$, and increased session time $(p<.0001)$, relative to SAL. PHY had no apparent effect on performance.

Lesions of the NBM impaired discrimination performance, as evidenced by a decrease in accuracy and successes and an increase in errors. Lesions did not interfere with rate of responding nor did they appear to affect general activity levels. Results suggest that NBM-lesioned animals have an impaired ability to attend to or discriminate between stimuli and consequently are unable to use relevant stimulus features (i.e., cue light position) in accurately guiding behavior.

As expected from results of Experiment 2, we found that SCO-treated animals showed decreased successes, decreased errors, and decreased responding; accuracy did not appear to be affected. Since responding in general is reduced, including errors, this suggests that SCO does not affect discrimination. This is in contrast to other reports that suggest discrimination may be disrupted (see Bartus et al., 1986; Brown \& Warburton, 1971), though these researchers used tasks and methods different from those conducted here.

PHY did not alleviate lesion-induced deficits. It is possible that our PHY dose may have been either too low (cf. Murray \& Fibiger, 1985) or too high (cf. Deutch, 1973; see also Dekker et al., 1991) or RF damage may have been too extensive (e.g., see Hepler et al., 1985).

\section{EXPERIMENT 4}

Because of the putative role of cholinergic systems in impaired memory in aged humans (see Kopelman, 1986), we expected that discrimination performance would deteriorate over time more in lesioned animals than in control animals.

\section{Method}

To test for time as a factor in deterioration or recovery of performance of lesioned animals, 12 months postlesion and 10 months after their last exposure to the task, surviving animals were retested on the operant task. No drugs were evaluated in this experiment. No experimental manipulations were conducted during the 10 -month hiatus. The rats were tested over five trials, with operant chamber settings kept at the animals' previous training levels (i.e., 3-sec target/10-sec distractor with 10 -sec delay schedule).

One additional test day was included in the statistical analyses: the last day of postsurgery testing prior to the 10-month hiatus (animal age, 208 days: D208). Data were analyzed using individual repeated measures ANOVAs for successes, errors, total responses, and session times. Newman-Keuls post hoc contrasts were conducted for specific between-groups effects, and single-degree-offreedom post hoc contrasts were conducted for specific withingroups effects.

After the conclusion of the fifth trial, the rats were sacrificed for histological evaluation. The animals were anesthetized with pentobarbital (Sigma Chemical, St. Louis, MO) and subsequently per- fused with $0.9 \%$ saline followed by $10 \%$ formalin. Brains were extracted and placed in a $10 \%$ formalin $/ 30 \%$ sucrose solution for $48 \mathrm{~h}$ prior to freezing and sectioning. Alternate sections ( $20 \mu \mathrm{m}$ thick) through NBM, and every 9 th and 10 th remaining sections were stained with thionin (Hodge \& Butcher, 1979). Lesion characteristics were assessed qualitatively, and lesion placement verified.

To provide histochemical verification of lesion placement, 8 new rats were evaluated for acetylcholinesterase (AChE) activity following bilateral NBM lesions. These rats were age-matched with the rats used in Experiments 1-4, with respect to age at surgery, but otherwise had no exposure to the task or experimental testing. All rats were prepared for surgery as detailed in Experiment 3 , with postoperative care and feeding given as described, but were sacrificed 1 week following surgery. Five rats received bilateral RF lesions of the NBM, and 3 rats underwent sham surgery (i.e.. no current was applied). The animals were sacrificed and perfused as described above, and brains were frozen and sectioned at $20 \mu \mathrm{m}$. Tissue was then processed for AChE using the method of Karnovsky and Roots (1954) and qualitatively assessed for differences in cortical AChE staining density.

\section{Results and Discussion}

Over the 10-month hiatus, several rats from both lesion and control groups were sacrificed due to age-related health problems. Also, animals excluded from statistical analysis in Experiment 3 were excluded from Experiment 4 . Nine rats with NBM lesions and 9 rats without lesions were evaluated in Experiment 4. The rats appeared active and in good health prior to testing.

\section{Behavioral Data}

Between-groups effects. As shown in Figure 4, relative to controls, overall tests showed that lesions decreased successes $[F(1,16)=7.71, p<.0135]$ and increased session time $[F(1,16)=7.41, p<.0151]$. No overall between-groups effects were observed for accuracy, errors, or total responding. Newman-Keuls post hoc contrasts showed that lesions reduced successes at D208 $(p<.05)$, D508 $(p<.05)$, and D516 $(p<.05)$, relative to controls, and increased session time at D510 $(p<.05)$, $\mathrm{D} 512(p<.05)$, and D514 $(p<.05)$, relative to controls.

Within-groups effects. Overall, within-groups effects were observed for accuracy $[F(5,80)=21.045, p<$ $.0001]$, successes $[F(5,80)=8.18, p<.0001]$, errors $[F(5,80)=57.82, p<.0001]$, total responding $[F(5,80)=$ $31.82, p<.0001]$, and session time $[F(5,80)=6.48, p<$ $.0001]$. Single-degree-of-freedom post hoc contrasts showed that rats at D508 had reduced accuracy ( $p<$ $.0001)$, reduced successes $(p<.0005)$, increased errors $(p<.0001)$, increased total responses $(p<.0001)$, and increased session time $(p<.0008)$, relative to D208. Rats at D510 also showed increased session time ( $p<$ .0388 ). Rats at D516 showed decreased accuracy ( $p<$ $.0166)$ and decreased errors $(p<.0275)$, relative to D208.

Performance of NBM-lesioned animals was initially worse than that of the controls. However, NBM-lesioned animals did show recovery and improved their performance over time. We have also found this to be the case with animals given ibotenic acid lesions of the NBM (Butt et al., 1990). Many other reports have shown sim- 

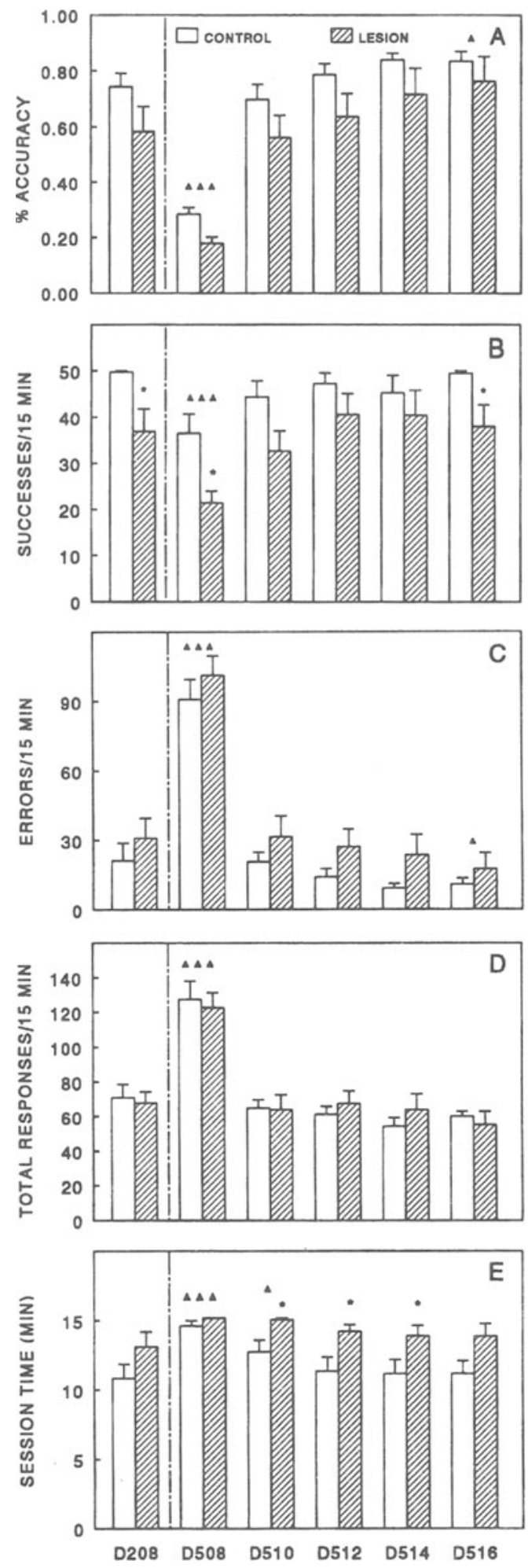

Figure 4. Performance in lesioned animals 1 year after surgeries and 10 months after last task exposure remained impaired compared with nonlesioned (sham and nonsurgery) animals. D208, last test day, postsurgery; D508, first test day, 10 months following D208 (note that numbers refer to animal age in days). Comparison between control (sham and nonsurgery) and lesioned groups: ${ }^{\star} p<.05$. Comparison within groups: $\Delta p<.05 ; \Delta \Delta \Delta p<.001$. ilar recovery with postoperative practice following NBM lesions (see review by Olton \& Wenk, 1987).

\section{Histology}

A typical NBM lesion is represented in Figure 5. Examination of thionin-stained sections showed that lesions were located in the ventromedial region of the globus pallidus, which contains the diffuse cells of the NBM. Lesion sites were characterized by necrosis of cell bodies and fibers of passage and by an intense gliotic reaction. Lesions were centered in the substantia innominata, extending approximately $1 \mathrm{~mm}$ anterior and $1 \mathrm{~mm}$ posterior. Of the surgery animals not included in statistical comparisons, histologies showed lesions that were unexpectedly large and improperly centered (i.e., lesions were almost twice the volume of the lesion presented in Figure 5 in nearly all cases and were not centered in the substantia innominata).

AChE-reactive staining was greater in prefrontal and parietal cortices (see Figures $6 \mathrm{~A}$ and $6 \mathrm{C}$, respectively) of control rats than in the same regions of NBM-lesioned animals (see Figures $6 \mathrm{~B}$ and $6 \mathrm{D}$ ). This suggests that the loss of NBM cells was responsible for the decreased AChE activity and that cholinergic transmission to the neocortex was reduced in lesioned animals.

Examinations of lesion placement and size were comparable to those seen by Hepler et al. (1985). RF lesions of the NBM in their study produced significant decreases in choline acetyltransferase, a marker for $\mathrm{ACh}$, in frontal cortex. We observed a decrease in AChE production following lesions. Both prefrontal and parietal AChE production was reduced in lesioned animals, relative to controls, suggesting that neocortical cholinergic input was reduced in lesioned animals.

\section{GENERAL DISCUSSION}

RF lesions of the NBM or SCO administration resulted in different types of performance deficits in our task. PHY was ineffective in reversing either type of deficit. SCO-induced deficits appeared to induce response inhibition rather than memory loss, and NBM lesions induced a deficit in discrimination ability. In contrast, early studies on the role of ACh involvement in memory demonstrated that SCO and atropine, cholinergic antagonists, interfered with avoidance and discrimination behavior (Kirk et al., 1988; see also Dekker et al., 1991). Also, studies on the cholinergic agonists PHY and diisopropylfluoro-phosphate, which block AChE activity and lead to increased levels of $\mathrm{ACh}$, showed that these drugs generally improved memory for certain tasks (Aigner \& Mishkin, 1986; Santucci et al., 1989; see also Dekker et al., 1991).

More recent studies, however, have shown that the role of $\mathrm{ACh}$ in memory formation and retrieval is more complex than Deutsch's (1973) original hypothesis that memory formation involves an optimal and timedependent level of $\mathrm{ACh}$ in the cholinergic synapse (see Dekker et al., 1991). Although ACh is probably involved 


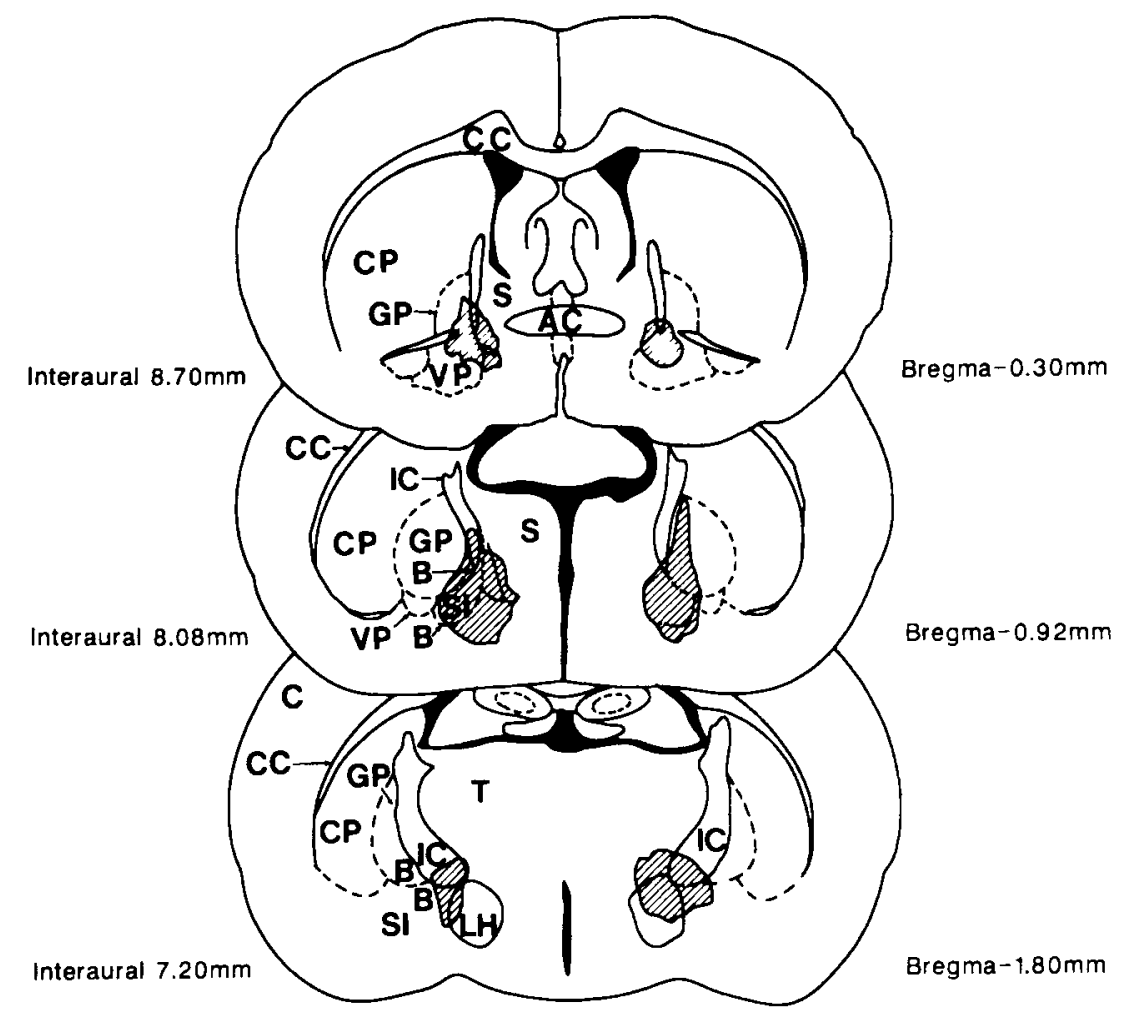

Figure 5. Drawings of coronal sections showing representative bilateral radio-frequency lesions of the NBM area. Hatched areas indicate the extent of cell loss and gliosis. Lesions were centered in the substantia innominata (SI) and extended into portions of ventral pallidum (VP), globus pallidus (GP), lateral hypothalamus (LH), and striatal areas (S). B, nucleus basalis magnocellularis; $\mathrm{AC}$, anterior commissure; $\mathrm{CC}$, corpus callosum; $\mathrm{CP}$, caudate putamen; $I C$, internal capsule. Drawings were made using a projection microscope and were later adapted to the Paxinos and Watson (1986) stereotaxic atlas.

in learning and memory processes (see Kopelman, 1986), the relationship is quite complex and depends upon a number of factors. Task difficulty, factors that affect motivation, and the nature of reward and punishment involved in the task are all contributing factors as well (see Dunnett, 1985). Suppression or enhancement of general ACh activity may not be adequate to affect learning or memory in every situation.

In our task, PHY did not have any apparent affect on SCO-treated animals. Other researchers have found that PHY, when given in small doses $(0.025-0.075 \mathrm{mg} / \mathrm{kg})$, improves performance for discrimination learning in Tmazes (Cox \& Tye, 1973; Whitehouse, 1966) and increases passive avoidance learning (Rosic \& Bignami, 1970). However, Cox and Tye (1973) showed that as task difficulty increases, a larger dose of PHY is necessary to obtain a facilitative effect, possibly suggesting that greater demands are placed on cholinergic systems with increased task difficulty. Considering that our task, with a differential discrimination element, required not only intact memory but unimpaired attention, accurate discrimination, and unimpaired sensorimotor processes, our dose $(0.03125 \mathrm{mg} / \mathrm{kg})$ may have been too low to affect performance of SCO-treated animals. It is possible that although PHY increases performance for simpler tasks by increasing general arousal, more difficult tasks are unaffected, or negatively affected, because lower arousal states are better for performance in those situations than are the higher arousal produced by PHY (reminiscent of the Yerkes-Dodson effect; see Yerkes \& Dodson, 1908). Additionally, our test of PHY with SCO used a relatively high dose of SCO $(0.125 \mathrm{mg} / \mathrm{kg})$; the $0.03125-\mathrm{mg} / \mathrm{kg}$ dose of PHY may have been too low to counteract the deficits caused by the high SCO treatment. Bohdanecky and Jarvik (1967) showed that $0.5-\mathrm{mg} / \mathrm{kg}$ PHY antagonized $1.0-\mathrm{mg} / \mathrm{kg} \mathrm{SCO}$ in a passive avoidance task. If it is necessary to have a $50 \%$ ratio of $\mathrm{PHY}$ to SCO to improve performance in a passive avoidance task, it may be necessary to use a much higher ratio for more difficult tasks, such as ours. Our ratio of PHY to SCO was approximately $25 \%$.

SCO administration alone increased session time and generally inhibited responding. These findings are consistent with the findings of Dunnett (1985), in that more complex tasks may be more sensitive to peripheral effects of SCO than simpler tasks, and with the findings of Broks et al. (1988) and Cheal (1981), in that aninals behaved in a manner consistent with an attention impair- 

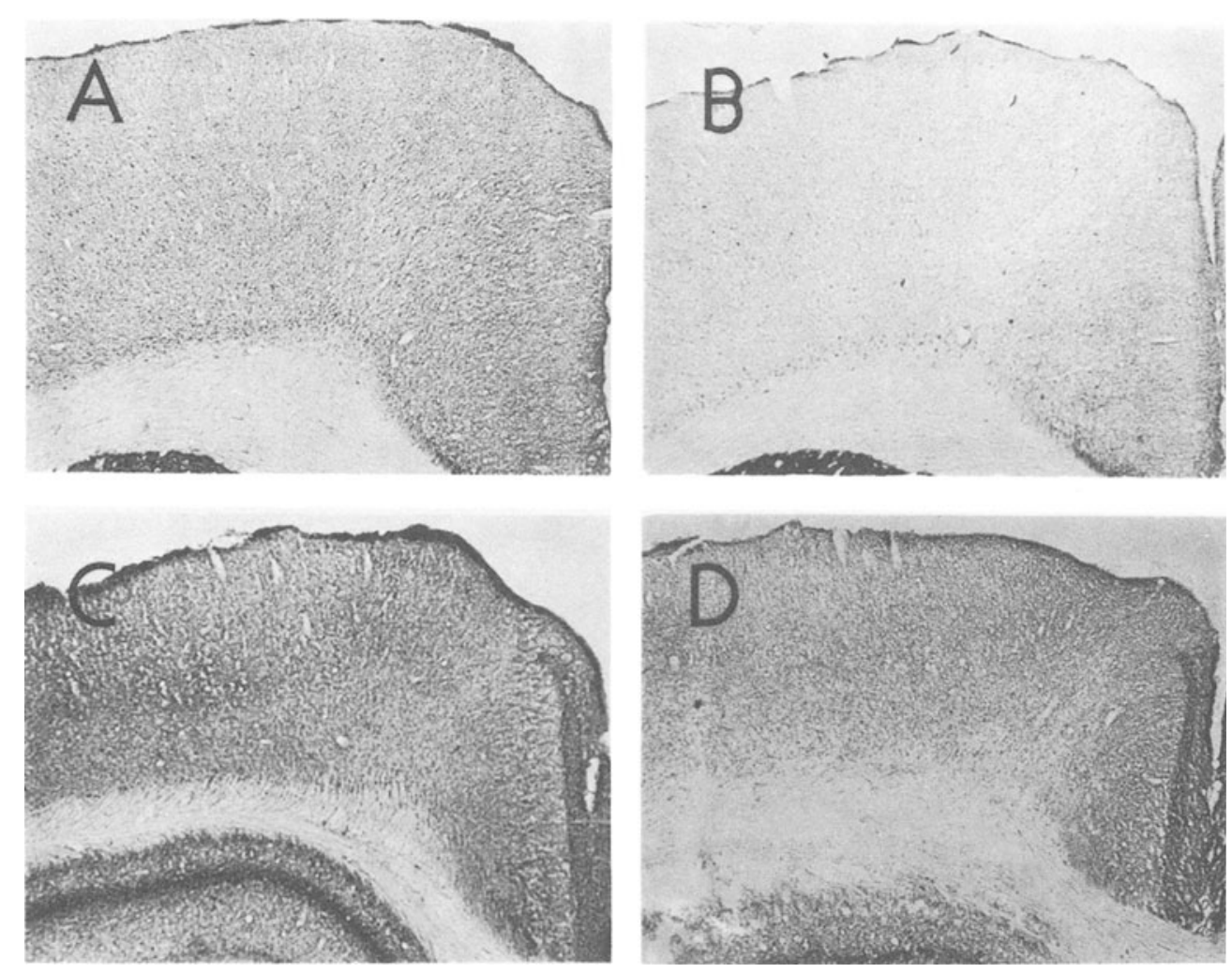

\begin{abstract}
Figure 6. Representative coronal sections of $\mathrm{AChE}$-stained tissue from control and NBM-lesioned animals.

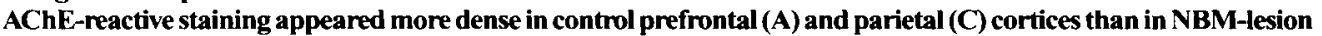
prefrontal (B) and parietal (D) cortices, suggesting that cholinergic innervation of the neocortex was reduced in lesioned animals.
\end{abstract}

ment (i.e., reduced successes and overall responding are consistent with an attentional impairment for this task). It remains difficult, however, to comment on the effects of SCO on discrimination or memory, because the drug reduced errors as well as successes. In our task, SCO's primary effect seemed to be a general response inhibition, perhaps resulting from impaired attentional processes. Sarter (1990) found that SCO did not affect memory retrieval in a conditional visual operant discrimination task but impaired responding. Sarter's (1990) findings, and the work of Renner, Dodson, and LeDuc (1992) on the effects of SCO on free-exploration activity, support the conclusion that SCO does not directly affect memory but does affect responding.

It has been argued that lesions of the NBM interfere with working memory but not reference memory (e.g., Beninger, Jhamandas, Boegman, \& El-Defrawy, 1989). This argument has been supported by several studies in which a variety of lesion techniques and learning paradigms have been used (Bartus et al., 1985; Beninger et al., 1989; Biggan, Beninger, Cockhill, Jhamandas, \& Boegman, 1991). For example, rats with preoperative training showed a working memory deficit when given ibotenic acid lesions of the NBM and tested in a T-maze alternation task (Hepler et al., 1985); NBM lesions did not af- fect reference memory but did affect working memory. Biggan et al. (1991) showed that preoperatively trained rats given quisqualate lesions of the NBM and tested in a double-Y maze had intact reference memory and impaired working memory.

Although our task did not allow differentiation between working and reference memory, our data are consistent with the possibility that NBM lesions interfered with discrimination (the ability to distinguish between two stimuli similar in nature) by disrupting attention. Sustained attention is necessary over the course of a trial to accurately distinguish reward versus nonreward intervals. Lesioned animals were able to respond with some successes, evidently retaining memory for the task basics. However, their accuracy was sharply decreased, relative to controls. This would be consistent with a generalized attentional deficit, as disrupted attention would lead to missed opportunities for reward, decreased successes, and increased errors. These results are consistent with other work in our lab in which animals given bilateral infusions of ibotenic acid into the NBM before training showed difficulty in forming associations between specific relevant stimulus features and reinforcement opportunities (Butt \& Hodge, 1995). The work with ibotenic acid lesions suggests that information pro- 
cessing of stimulus features is an important function of the NBM and may be part of a more global process of attention (Hodges, Allen, Sinden, Lantos, \& Gray, 1991).

PHY did not improve performance of lesioned animals. Although PHY has been shown to improve performance in different tasks in a number of studies (Dunnett, 1985; Haroutunian, Barnes, \& Davis, 1985; Haroutunian, Kanof, \& Davis, 1985, 1989; Miyamoto, Narumi, Nagaoka, \& Coyle, 1989; Miyamoto et al., 1989; Murray \& Fibiger, 1985, 1986; Santucci et al., 1989; Tilson et al., 1988), not all reports have found improved performance, possibly because the dose of PHY used may have been too low (Aigner et al., 1987; Robbins et al., 1989; Thal, Dokla, \& Armstrong, 1988). Task complexity and optimum dosage may be interrelated. Our dose may have been too low $(0.03125 \mathrm{mg} / \mathrm{kg})$ to have had an ameliorative effect in this task. Murray and Fibiger $(1985,1986)$ have found improvement in NBM-lesioned animals after administration of PHY, in both T-maze and radial arm maze tests, but used relatively high doses in their studies. Additionally, the nature of our lesion technique may have precluded PHY's effects. Haroutunian, Kanof, Tsuboyama, Campbell, and Davis (1986) suggest that the addition of noradrenergic and cholinergic damage may affect the ability of PHY to reverse performance deficits. RF lesions destroy not only neuronal perikarya at the site of the NBM but fibers of passage as well. It is likely that some dopaminergic and noradrenergic innervation of the cortex was disrupted. PHY would not be expected to reverse these effects.

In general, results from the present experiments are consistent with the position that cholinergic systems play important roles in the performance of learned tasks (Broks et al., 1988; Buhot, Soffie, \& Poucet, 1989; Cheal, 1981). Pharmacologically induced cholinergic suppression, by i.p. infusion of SCO, induced a generalized response inhibition. Whether SCO directly interfered with discrimination or memory remains unclear. In contrast, NBM lesions clearly impaired discrimination, possibly by interfering with attentional processes. These deficits persisted over time, although the magnitude of the difference between experimental and control animals diminished with resumed practice. In conclusion, cholinergic systems in general and NBM systems in particular seem more involved with stimulus-processing characteristics of task performance than with memory per se.

\section{REFERENCES}

Aigner, T. G., \& Mishisin, M. (1986). The effects of physostigmine and scopolamine on recognition memory in monkeys. Behavioral Neuroscience, 45, 81-87.

Aigner, T. G., Mitchell, S. J., Aggleton, J. P., Delong, M. R., Struble, R. G., Price, D. L., Wenk, G. L., \& Mishkin, M. (1987). Effects of scopolamine and physostigmine on recognition memory in monkeys with ibotenic-acid lesions of the nucleus basalis of Meynert. Psychopharmacology, 92, 292-300.

Bartus, R. T., Flicker, C., Dean, R. L., Pontecorvo, M., \& FiguelREDO, J. (1986). Behavioral and biochemical effects of nucleus basalis magnocellularis lesions: Implications and possible relevance to understanding or treating Alzheimer's disease. Progress in Brain Research, 70, 345-361.
Bartus, R. T., Flicker, C., Dean, R. L., Pontecorvo, M., FigueiREDO, J. C., \& Fisher, S. K. (1985). Selective memory loss following nucleus basalis lesions: Long term behavioral recovery despite persistent cholinergic deficits. Pharmacology, Biochemistry \& Behavior, 23, 125-135.

Beatty, W. W., \& Bierley, R. A. (1986). Scopolamine impairs encoding and retrieval of spatial working memory in rats. Physiological Psychology, 14, 82-86.

Beninger, R. J., Jhamandas, K., Boegman, R. J., \& El-Defrawy, S. R. (1989). Effects of scopolamine and unilateral lesions of the basal forebrain on T-maze spatial discrimination and alternation in rats. Pharmacology, Biochemistry \& Behavior, 24, 1353-1360.

Biggan, S. L., Beninger, R. J., Cockhill, J., Jhamandas, K., \& BoEgman, R. J. (1991). Quisqualate lesions of the rat NBM: Selective effects on working memory in a double Y-maze. Brain Research Bulletin, 26, 613-616

BOHDANECKY, Z., \& JARVIK, M. E. (1967). Effect of $d$-amphetamine and physostigmine upon acquisition and retrieval in a single trial learning task. Archives Internationales de Pharmacodynamie et de Therapie, 170, 58-65.

Broks, P., Preston, G. C., Tralb, M., Poppleton, P., Ward, C., \& STAHL, S. M. (1988). Modeling dementia: Effects of scopolamine on memory and attention. Neuropsychologia, 26, 685-700.

Brown, K., \& Warburton, D. M. (1971). Attenuation of stimulus sensitivity by scopolamine. Psychonomic Science, 22, 297-298.

Buhot, M.-C., Soffie, M. \& Povicet, B. (1989). Scopolamine affects the cognitive processes involved in selective object exploration more than locomotor activity. Psychobiology, 17, 409-417.

Butt, A. E., Dencoff, J. E., Cooper, B. G., Nopp-Dvorak, K., \& HodGe, G. K. (1990). Differential impairment of discrimination learning in rats due to nucleus basalis magnocellularis lesions or scopolamine treatment. Society for Neuroscience Abstracts, 16, 905

ButT, A. E., \& HodGE, G. K. (1994). Negative patterning discrimination performance is impaired in rats with bilateral quisqualic acid lesions of the nucleus basalis magnocellularis. Society for Neuroscience Abstracts, 20, 1212.

Butt, A. E., \& Hodge, G. K. (1995). Acquisition, retention, and extinction of operant discriminations in rats with nucleus basalis magnocellularis lesions. Behavioral Neuroscience, 109, 699-713.

Cheal, M.-L. (1981). Scopolamine disrupts maintenance of attention rather than memory processes. Behavioral \& Neural Biology, 33. 163-187.

Cox, T., \& TYE, N. (1973). Effects of physostigmine on acquisition of a position discrimination in rats. Neuropharmacology, 12, 477-484.

Dekker, A. J. A. M., Connor, D. J., \& Thal, L. J. (1991). The role of cholinergic projections from the nucleus basalis in memory. Neuroscience \& Behavioral Reviews, 15, 299-317.

DEuTSCH, J. A. (1973). The cholinergic synapse and the site of memory. In J. A. Deutsch (Ed.), The physiological basis of memory (pp. 59-76). New York: Academic Press.

DunNeTt, S. B. (1985). Comparative effects of cholinergic drugs and lesions of nucleus basalis or fimbria-fornix on delayed matching in rats. Psychopharmacology, 87, 357-363.

Flicker, C., Dean, R. L., Watkins, D. L., Fisher, S. K., \& Bartus, R. T. (1983). Behavioral and neurochemical effects following neurotoxic lesions of a major cholinergic input to the cerebral cortex in the rat. Pharmacology, Biochemistry \& Behavior, 18, 973981.

Haroutunian, V., Barnes, E., \& Davis, K. L. (1985). Cholinergic modulation of memory in rats. Psychopharmacology, 87, 266-271.

Haroutunian, V., Kanof, P. D., \& Davis, K. L. (1985). Pharmacological alleviation of cholinergic lesion induced memory deficits in rats. Life Sciences, 37, 945-952.

Haroutunian, V., Kanof, P. D., \& Davis, K. L. (1989). Interactions of forebrain cholinergic and somatostatinergic systems in the rat. Brain Research, 496, 98-104.

Haroutunian, V., Kanof, P. D., Tsuboyama, G. K., Campbell, G. A., \& Davis, K. L. (1986). Animal models of Alzheimer's disease: Behavior, pharmacology, transplants. Canadian Journal of Neurological Sciences, 13, 385-393.

Hepler, D. J., Olton, D. S., Wenk, G. L., \& Coyle, J. T. (1985). Lesions in nucleus basalis magnocellularis and medial septal area of 
rats produce qualitatively similar memory impairments. Journal of Neuroscience, 5, 866-873.

Hodge, G. K., \& Butcher, L. L. (1979). Role of pars compacta of the substantia nigra in circling behavior. Pharmacology, Biochemistry \& Behavior, 10, 695-709.

Hodges, H., Allen, Y., Sinden, J., Lantos, P. L., \& Gray, J. A. (1991). Effects of cholinergic-rich neural grafts on radial maze performance of rats after excitotoxic lesions of the forebrain cholinergic projection system: II. Cholinergic drugs as probes to investigate lesioninduced deficits and transplant-induced functional recovery. Neuroscience, 3, 609-623.

Karnovsky, M. J., \& Roots, L. A. (1954). A 'direct-coloring' thiocholine method for acetylcholinesterase. Journal of Histochemistry \& Cytochemistry, 12, 219-221.

Kirk, R. C., White, K. G., \& McNaughton, N. (1988). Low dose scopolamine affects discriminability but not rate of forgetting in delayed conditional discrimination. Psychopharmacology, 96, 541546.

KoPELMAN, M. D. (1986). The cholinergic neurotransmitter system in human memory and dementia: A review. Quarterly Journal of Experimental Psychology, 38A, 535-573.

Marston, H. M., Garcha, H. S., Robbins, T. W., \& Stolerman, I. P. (1992). Drug discrimination learning in rats with excitotoxic lesions of nucleus basalis and ventral globus pallidus. Behavioural Brain Research, 51, 93-102.

Miyamoto, M., Narumi, S., Nagaoka, A., \& Coyle, J. T. (1989). Effects of continuous infusion of cholinergic drugs on memory impairment in rats with basal forebrain lesions. Journal of Pharmacology \& Experimental Therapeutics, 248, 825-834.

Miyamoto, M., Shintani, M., Nagaoka, A., \& Nagawa, Y. (1985). Lesioning of the rat basal forebrain leads to memory impairments in passive and active avoidance tasks. Brain Research, 328, 97-104.

Murray, C. L., \& Fibiger, H. C. (1985). Learning and memory deficits after lesions of the nucleus basalis magnocellularis: Reversal by physostigmine. Neuroscience, 14, 1025-1032.

Murray, C. L., \& Fibiger, H. C. (1986). Pilocarpine and physostigmine attenuate spatial memory impairments produced by lesions of the nucleus basalis magnocellularis. Behavioral Neuroscience, $\mathbf{1 0 0}$, 23-32.

Olton, D. S., \& WENK, G. L. (1987). Dementia: Animal models of the cognitive impairment produced by degeneration of the basal forebrain cholinergic system. In H. Y. Meltzer (Ed.), Psychopharmacology: A third generation of progress (pp. 941-953). New York: Raven.

Paxinos, G., \& Watson, C. (1986). The rat brain in stereotaxic coordinates. Orlando, FL: Academic Press.

Renner, M. J., Dodson, D. L., \& LeDuc, P. A. (1992). Scopolamine suppresses both locomotion and object contact in a free-exploration situation. Pharmacology, Biochemistry \& Behavior, 41, 625-636.

Robbins, T. W., Everitt, B. J., Ryan, C. N., Marston, H. M., Jones, G. H., \& PAGE, K. J. (1989). Comparative effects of quisqualic and ibotenic acid-induced lesions of the substantia innominata and globus pallidus on the acquisition of a conditional visual discrimination: Differential effects on cholinergic mechanisms. Neuroscience, 28, 337-352.

Rosic, N., \& Bignami, G. (1970). Depression of 2-way avoidance learning and enhancement of passive avoidance learning by small doses of physostigmine. Neuropharmacology, 9, 311-316.

Salamone, J. D., Beart, P. M., Alpert, J. E., \& Iversen, S. D. (1984). Impairment in T-maze reinforced alternation performance following nucleus basalis magnocellularis lesions in rats. Behavioural Brain Research, 13, 63-70.

Santucci, A. C., Kanof, P. D., \& Haroutunian, V. (1989). Effect of physostigmine on memory consolidation and retrieval processes in intact and nucleus basalis-lesioned rats. Psychopharmacology, 99, 70-74.

SARTER, M. (1990). Retrieval of well-learned propositional rules: Insensitive to changes in activity of individual neurotransmitter systems? Psychobiology, 18, 451-459.

Thal, L. J., Dokla, C. P. J., \& Armstrong, D. M. (1988). Nucleus basalis lesions: Lack of biochemical and immunocytochemical recovery and effect of cholinesterase inhibitors on passive avoidance. Behavioral Neuroscience, 102, 852-860.

Tilson, H. A., Mclamb, R. L., Shaw, S., Rogers, B. C., PediadiTAKIS, P., \& COOK, L. (1988). Radial arm maze deficits produced by colchicine administered into the area of the nucleus basalis are ameliorated by cholinergic agents. Brain Research, 438, 83-94.

Wenk, G. L., Cribrs, B., \& MCCall, L. (1984). Nucleus basalis magnocellularis: Optimal coordinates for selective reduction of choline acetyltransferase in frontal neocortex by ibotenic acid injections. Experimental Brain Research, 56, 335-340.

WhitehousE, J. M. (1966). Effects of physostigmine on discrimination learning. Psychopharmacologia, 9, 183-188.

Wozniak, D. F., Stewart, G. R., Finger, S., \& Olney, J. W. (1989). Comparison of behavioral effects of nucleus basalis magnocellularis lesions and somatosensory cortex ablation in the rat. Neuroscience, 32, 685-700

YERKES, R. M., \& DodSON, J. D. (1908). The relation of strength of stimulus to rapidity of habit-formation. Journal of Comparative Neurology \& Psychology, 18, 459-482.

(Manuscript received October 2, 1994; revision accepted for publication June 13,1995.) 